\title{
Masking white spots of enamel in caries lesions with a non-invasive infiltration technique in vitro
}

\author{
X.-Y. Ou, Y.-H. Zhao, X.-K. Ci and L.-W. Zeng \\ Department of Preventive Dentistry, \\ The Affiliated Stomatological Hospital of Nanchang University, \\ Nanchang, China \\ Corresponding author: L.-W. Zeng \\ E-mail: liweizengen@126.com
}

Genet. Mol. Res. 13 (3): 6912-6919 (2014)

Received July 22, 2013

Accepted February 10, 2014

Published August 29, 2014

DOI http://dx.doi.org/10.4238/2014.August.29.14

\begin{abstract}
We investigated the treatment effect of non-invasive infiltration on early caries caused by different degrees of enamel demineralization. Forty specimens of early enamel caries were prepared and divided into low and high demineralization groups. After treatment with non-invasive infiltration, the specimens were placed under cariogenic conditions. Color measurements were determined using a spectrophotometer 4 times to obtain chromatism values $(\Delta \mathrm{E} 1-$ $\Delta \mathrm{E} 4)$, including before and after production of artificial caries, and after infiltration treatment and re-demineralization. The effects of color change on early caries using non-invasive infiltration were compared between the 2 demineralization groups. Color differences before the production of artificial caries and after infiltration treatment and redemineralization could not be distinguished by direct observation. Color differences after the production of artificial caries and after infiltration treatment and re-demineralization could be distinguished by direct observation. There were no significant differences in the 4 chromatism values $(\Delta \mathrm{E} 1-\Delta \mathrm{E} 4)$ between the 2 groups. Non-invasive infiltration
\end{abstract}


showed an excellent ability to mask white spot lesions and maintained high color stability. Treatment of high and low demineralization of enamel had the same masking effect.

Key words: Non-invasive infiltration; Early caries; Demineralization; White spot lesions

\section{INTRODUCTION}

Clinical manifestations of early caries present as a dull and slightly rough enamel surface with chalky or brown caries spots that have not yet formed cavities or defects. Typically, the clinical treatment for such lesions is to promote the remineralization of early caries. However, because of the long course of treatment involved requiring high patient compliance, several limitations may occur, such as production of resistant strains (Wang and Tang, 2005). In treatments of filling restorations, even very small dental preparations may lead to the loss of healthy tooth tissue (Mueller et al., 2006). Non-invasive infiltration is a non-invasive treatment method that avoids removal of the tooth tissue. One treatment is sufficient to mask the chalky lesions, improve the appearance, and block ongoing demineralization of early caries, making treatment of early caries simple, fast, effective, and non-invasive (Meyer-Lueckel and Paris, 2008; Paris and Meyer-Lueckel, 2010; Paris et al., 2007, 2010).

Non-invasive infiltration technology was proposed and developed in Charité and Kiel University, Berlin, Germany. In 1976, infiltration treatment for natural and artificial chalk-like lesions was proposed by Davila et al. (1975). Studies of non-invasive infiltration technology in vitro have been conducted since 2000, and clinical studies in vivo are currently being developed. Previous studies have demonstrated that this technology can effectively improve the chalky white spots caused by enamel demineralization, and shows high color stability after improvement (Rocha Gomes et al., 2011). Even for old white spots caused by enamel demineralization, infiltration treatment shows some degree of improvement (Neuhaus et al., 2010). An improvement effect of infiltration treatment on chalky white spots formed during orthodontic process has also been clearly observed, but was less effective for white spots caused by insufficient enamel mineralization (Kim et al., 2011). Whether this infiltration effect is affected by the extent of demineralization is unknown.

In the present study, established specimens of early caries in vitro were treated with non-invasive infiltration. The efficacy of masking the chalky lesions was observed. We also investigated the effect of treating early caries caused by different degrees of enamel demineralization and determined whether this effect persisted in a cariogenic environment.

\section{MATERIAL AND METHODS}

\section{Samples}

Healthy, caries-free orthodontic subtrahend premolars were freshly extracted from children aged 12-14 years. After the occlusal surface was blow dried, 40 samples without caries, enamel hypoplasia, or other abnormalities were collected by observation under a stereomicroscope. The surfaces of the calculus, alveolar bone, and soft tissue were removed, and 
the root of the tooth was amputated using a carborundum disk at $1 \mathrm{~mm}$ of the cemento-ename junction to prepare $5 \times 5 \times 2$-mm enamel block. The enamel blocks obtained were immersed in a $0.1 \%$ thymol-saturated aqueous solution for further analysis. This study was conducted in accordance with the Declaration of Helsinki and with approval from the Ethics Committee of the Affiliated Stomatological Hospital of Nanchang University (Permit Number: 20110025301). Written informed consent was obtained from the legal guardians of all participants.

\section{Preparation of artificial cariogenic solution}

Artificial cariogenic solution containing $0.2442 \mathrm{~g} \mathrm{NaCl}, 0.2992 \mathrm{~g} \mathrm{KH}_{2} \mathrm{PO}_{4}, 1.56 \times 10^{-3}$ $\mathrm{g} \mathrm{KCl}, 3.0 \mathrm{~g} \mathrm{HAc}$, and $56.0 \mathrm{~g} \mathrm{KOH}$ was prepared. The compounds above were dissolved in $1000 \mathrm{~mL}$ distilled water and the $\mathrm{pH}$ was adjusted to 4.6.

\section{Preparation of artificial saliva}

Artificial saliva containing $0.33 \mathrm{~g} \mathrm{KH}_{2} \mathrm{PO}_{4}, 0.34 \mathrm{~g} \mathrm{NaH}_{2} \mathrm{PO}_{4}, 1.27 \mathrm{~g} \mathrm{KCl}, 0.16 \mathrm{~g}$ $\mathrm{CNNaS}, 0.58 \mathrm{~g} \mathrm{NaCl}, 0.17 \mathrm{~g} \mathrm{CaCl}_{2}, 0.16 \mathrm{~g} \mathrm{NH}_{4} \mathrm{Cl}, 0.2 \mathrm{~g}$ urea, $0.03 \mathrm{~g}$ glucose, $0.002 \mathrm{~g}$ vitamin $\mathrm{C}$, and $2.7 \mathrm{~g}$ mucin was prepared. The regents above were dissolved in $1000 \mathrm{~mL}$ distilled water and the $\mathrm{pH}$ was adjusted to 6.8 .

\section{Specimen preparation of early caries}

Forty specimens were placed in a container to ensure that their enamels were entirely in contact with the artificial saliva; these samples were incubated for $12 \mathrm{~h}$. Next, all samples were soaked alternately in artificial cariogenic solution twice per day for $1 \mathrm{~h}$ and in artificial saliva twice per day for 11-h incubations for 15 days. The 2 solutions were changed daily and incubated in a water bath box (Shanghai Haima Industrial Co., Ltd. Medical Equipment Factory; Shanghai, China) at $37^{\circ} \mathrm{C}$.

The demineralization degree of the enamel surface of each sample was measured using DIAGNOdentPen (DDPen; Kavo, Germany) and recorded daily. The 4 corners of each sample were selected as measurement points, and the averages of the 4 measured values were recorded for sample readings. Based on specimen readings, samples were divided into 2 groups $(\mathrm{N}=20$ per group): Group I, low demineralization group (values 14-20) and Group II, high demineralization group (values 21-30).

\section{Coating penetration of resin}

According to the requirements for the product use of infiltration resin ICON (DMG; Bielefeld, Germany), after polishing using a rubber cup to clean the tooth surface, the sample was etched with $15 \%$ hydrochloric acid for 2 min and rinsed for $30 \mathrm{~s}$ with a water gun. An air gun was used to dry the sample for $30 \mathrm{~s}$ and $99 \%$ ethanol desiccant was injected into the demineralization site and allowed to remain for $30 \mathrm{~s}$. The sample was then completely dried using an air gun. Coat infiltration resin was applied at the demineralization site and left for 3 min, followed by irradiation for $40 \mathrm{~s}$ using a light-curing unit (Mini LED; Sately, France). The sample was coated a second time for $1 \mathrm{~min}$ and irradiated for $40 \mathrm{~s}$. 


\section{Re-demineralization treatment}

Forty specimens were again placed in artificial cariogenic solution or artificial saliva and treated as described above.

\section{Color measurement}

Color measurements for the 40 samples were performed 4 times. Before the production of artificial caries, the enamel blocks obtained were polished using a rubber cup at low speed and rinsed repeatedly with distilled water. After being blow dried, each window of the sample was determined using a CM-2300d spectrophotometer (Minolta; Osaka, Japan) for the first color measurement. After specimen preparation of early caries and production of artificial caries were completed, the second color measurement was performed. After infiltration treatment, the third color measurement was conducted after the infiltration resin was coated. For re-demineralization, after the samples were placed in artificial cariogenic solution for demineralization, the fourth color measurement was performed. All measurements were performed by one operator to reduce error.

White calibration was conducted. When the site of measurement on the specimen was vertically close to the window under the test, the built-in light source radiated light. A few seconds later, the results of measurement were displayed on the screen. The parameters included values of $L^{*}, a^{*}$, and $b^{*}$. The data pattern automatically used the average of the 3 measurement values.

To analyze measurement results, the chromatism value, $\Delta \mathrm{E}$ was used to quantify the overall differences of the 2 colors. The chromatism value was calculated using the following formula: $\Delta \mathrm{E}=\left[\left(\Delta \mathrm{L}^{*}\right)^{2}+\left(\Delta \mathrm{a}^{*}\right)^{2}+\left(\Delta \mathrm{b}^{*}\right)^{2}\right]^{1 / 2}$ by comparing the 4 measurement results. The USA National Bureau of Standard Unit (NBS unit) was employed as the unit of the color difference, in which $\triangle \mathrm{E}=1$ indicates one NBS unit. NBS is related to the degree of the visual differences of the human eye (Table 1).

\begin{tabular}{|c|c|}
\hline NBS unit & Degree of visual differences of the human eye \\
\hline $0.0-0.5$ & Little \\
\hline $0.5-1.5$ & Slight \\
\hline $1.5-3.0$ & Slightly \\
\hline $3.0-6.0$ & Obvious \\
\hline $6.0-12.0$ & Notable \\
\hline 12.0 or more & Highly significant \\
\hline
\end{tabular}

The minimum chromatism value established by the NBS for which the human eye can distinguish the difference of 2 objects in color is 1.5. Therefore, $\Delta \mathrm{E}=1.5 \mathrm{NBS}$ in this experiment was considered to be the critical value for visually distinguishing chromatic aberrations.

\section{Statistical analysis}

In this study, SPSS 12.0 was used for data collection and analysis (SPSS, Inc.; Chicago, IL, USA). The results of color measurement were analyzed using the Student $t$ test; statistical significance was set at $\mathrm{P}<0.05$. 


\section{RESULTS}

For the statistical analysis of the 4 color measurement results, a single sample-sided Student $t$ test was carried out using $\Delta \mathrm{E}=1.5$ as the overall average, assuming that $\Delta \mathrm{E}$ is not less than 1.5 (Tables 2 and 3).

\begin{tabular}{|c|c|c|c|c|c|c|}
\hline \multirow[t]{2}{*}{ Chromatic difference value } & \multicolumn{2}{|c|}{ Cases } & \multirow{2}{*}{$\begin{array}{l}\text { Composition } \\
\text { ratio for } \Delta \mathrm{E} \leq 1.5\end{array}$} & \multirow{2}{*}{$\begin{array}{l}\text { Mean and standard } \\
\text { deviation for } \Delta \mathrm{E}\end{array}$} & \multirow[t]{2}{*}{$t^{*}$} & \multirow[t]{2}{*}{$P$} \\
\hline & $\Delta \mathrm{E} \leq 1.5$ & $\Delta \mathrm{E}>1.5$ & & & & \\
\hline $\begin{array}{l}\Delta \mathrm{E} 1 \\
\Delta \mathrm{E} 2\end{array}$ & $\begin{array}{l}37 \\
36\end{array}$ & $\begin{array}{l}3 \\
4\end{array}$ & $\begin{array}{l}92.5 \% \\
90.0 \%\end{array}$ & $\begin{array}{l}0.848 \pm 0.292 \\
0.954 \pm 0.245\end{array}$ & -14.113 & $\begin{array}{l}<0.001 \\
<0.001\end{array}$ \\
\hline
\end{tabular}

*Single sample sided $t$ test was carried out using $\Delta \mathrm{E}=1.5$ as the overall average, assuming $\Delta \mathrm{E}$ is not less than 1.5.

\begin{tabular}{|c|c|c|c|c|c|c|}
\hline \multirow[t]{2}{*}{ Chromatic difference value } & \multicolumn{2}{|c|}{ Cases } & \multirow{2}{*}{$\begin{array}{l}\text { Composition } \\
\text { ratio for } \Delta \mathrm{E} \geq 1.5\end{array}$} & \multirow{2}{*}{$\begin{array}{l}\text { Mean and standard } \\
\text { deviation for } \Delta E\end{array}$} & \multirow[t]{2}{*}{$t^{*}$} & \multirow[t]{2}{*}{$\mathrm{P}$} \\
\hline & $\Delta \mathrm{E} \geq 1.5$ & $\Delta \mathrm{E}<1.5$ & & & & \\
\hline $\begin{array}{l}\mathrm{E} 33 \\
\Delta \mathrm{E} 4\end{array}$ & $\begin{array}{l}40 \\
38\end{array}$ & $\begin{array}{l}0 \\
2\end{array}$ & $\begin{array}{r}100.0 \% \\
950 \%\end{array}$ & $\begin{array}{l}2.319 \pm 0.912 \\
2.505 \pm 0.940\end{array}$ & $\begin{array}{l}5.684 \\
6.767\end{array}$ & $\begin{array}{l}<0.001 \\
<0.001\end{array}$ \\
\hline
\end{tabular}

*Single sample sided $t$ test was carried out using $\Delta \mathrm{E}=1.5$ as the overall average, assuming $\Delta \mathrm{E}$ is not less than 1.5.

Statistical analysis showed that $\Delta \mathrm{E} 1$ (difference in chromatic values obtained after non-invasive infiltration and before production of artificial caries) and $\Delta \mathrm{E} 2$ (difference in chromatic values obtained after a new acid challenge and before production of artificial caries) were less than 1.5 NBS, suggesting that the color difference could not be distinguished by direct observation. $\triangle \mathrm{E} 3$ (difference in chromatic values obtained after non-invasive infiltration and after production of artificial caries) and $\Delta \mathrm{E} 4$ (difference in chromatic values obtained after a new acid challenge and after production of artificial caries) was higher than 1.5 NBS, suggesting that the color difference could be distinguished by direct observation.

As shown in Table 4 and Figure 1, there were no significant differences in $\Delta \mathrm{E} 1, \Delta \mathrm{E} 2$, $\Delta \mathrm{E} 3$, and $\Delta \mathrm{E} 4$ between the low and high demineralization groups $(\mathrm{P}>0.05)$.

Table 4. Statistical results of four group comparisons of the chromatic difference value between groups I and
II.
\begin{tabular}{lcc}
\hline Chromatic difference value & $t$ & $\mathrm{P}$ \\
\hline$\Delta \mathrm{E} 1$ & 1.373 & 0.178 \\
$\Delta \mathrm{E} 2$ & 0.473 & 0.639 \\
$\Delta \mathrm{E} 3$ & -0.964 & 0.341 \\
$\Delta \mathrm{E} 4$ & -0.449 & 0.656 \\
\hline
\end{tabular}




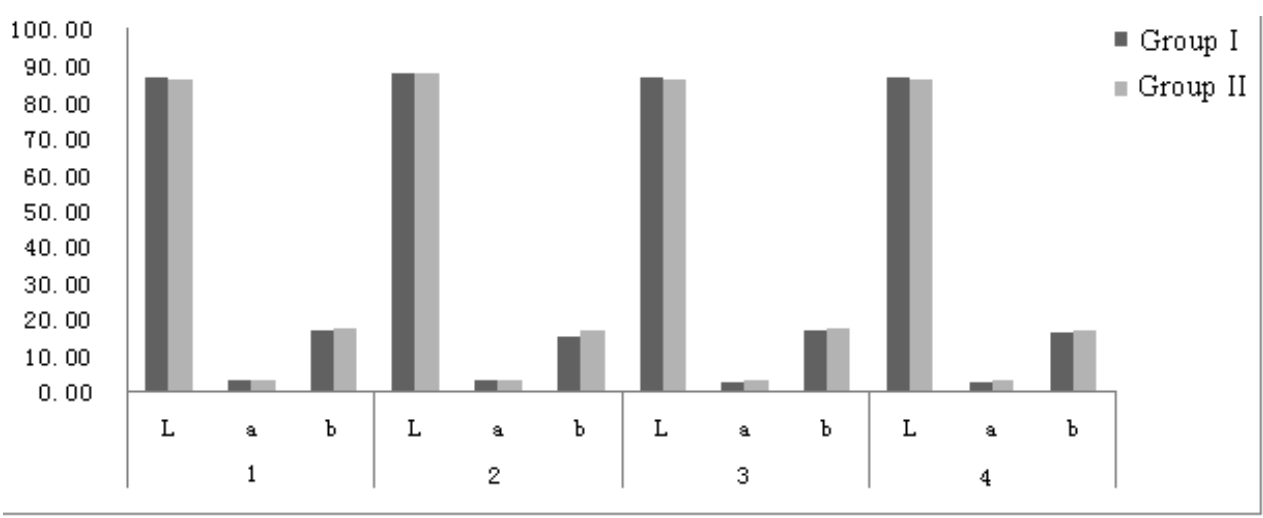

Figure 1. Histogram of L*, a*, $b^{*}$ value with color measurement in four times between groups I and II. $1=$ before the production of artificial caries; 2 =after the production of artificial caries; 3 =after the infiltration treatment; 4 $=$ re-demineralization.

\section{DISCUSSION}

The most common method of treating early caries is to use fluoride and remineralization. Fluoride is simply used for remineralization without considering the masking effect. A previous study showed that topical application of fluoride for the treatment of mouth early caries can promote remineralization and effectively prevent caries development (Yamazaki et al., 2007). If early lesions of dental caries are completely mineralized, a color change would be observed, resulting from color changes of the translucent enamel due to mineral content changes (Houwink, 1974; Brodbelt et al., 1981). However, this remineralization is superficial (Theuns et al., 1986; Anderson and Elliott, 2000). Although the enamel surface was mineralized, its body was more likely to decalcify; after remineralization, the optical reflectance in the body portion with caries lesions did not significantly decrease. This indicates that the body of carious lesions did not reach the same extent of remineralization as that of the surface. Therefore, after remineralization treatment, early caries lesions improved to some extent and the development of dental caries was terminated, but white spots were not improved.

Treatment of both non-invasive infiltration and remineralization can block the development of early caries. Chalky spots of early caries can also be improved by non-invasive infiltration. The improvement effect on the chalky spots formed in the orthodontic process is clear and better than those formed by poor enamel mineralization (Kim et al., 2011). This suggests that infiltration treatment does not have the same effect on all early caries. We examined whether different degrees of demineralization had the same effect on chalky lesions.

The results of the present study indicated that non-invasive infiltration technology can change the color of early caries lesions and achieve a good aesthetic effect by masking the chalky spots of early caries so that it appears close to its normal color. Previous studies also demonstrated that infiltration treatment could improve chalky spots caused by enamel demineralization, and that the color stability after improvement was very high (Rocha Gomes et al., 2011). Chalky spots caused by prior enamel demineralization could be improved by infiltration treatment (Neuhaus et al., 2010).

However, the masking effect is not affected by the extent of enamel demineralization; 
treatment of enamel with high and low levels of demineralization showed the same effect. Although the depth of infiltration can be affected by the degree of demineralization, the effects on color change were very similar. The reason may be that regardless of infiltration depth, the enamel surface and most of the carious lesion bodies were filled with infiltration resin matrix, resulting in nearly the same light reflectivity and performance for color measurement.

Some data in this experiment showed relatively large deviations, which may have been caused by fractionated determinations and measurement errors. Under the same environment and operator, it is difficult to control the measurement position, air humidity, and other factors that may have influenced light refraction. In addition, due to the radian of the sample surface, loss of a small amount of reflected light may have affected the measurements. Taking into account the problem of position deviations at different time points, continuous color measurement may be used to overcome this limitation.

Regarding the efficacy stability of non-invasive infiltration technology, in addition to maintenance in the short-term cariogenic environment, this technique should withstand the challenges of the complex oral environment for clinical application. More objective clinical observational studies are required to determine whether this method can maintain a good masking effect on the chalky spots.

Mueller et al. (2011) and Belli et al. (2011) observed the morphology after resinous infiltration of subsurface bovine enamel lesions and found that a large difference in surface roughness and morphology remained compared with normal enamel. Gloss on the object surface with the same chrominance will have a significant impact on the appearance. A smooth surface with high gloss has strong light with specular reflection and weak light of diffused reflection. The rough surface, or that with low gloss, shows weak light of specular reflection and strong light of diffused reflection. Typically, when observing the color of an object, one should avoid the angle of specular reflections, and diffused reflection light should be used as a reference to determine the object's color. Dietschi et al. (1994) pointed out that the average value of the resin color difference was related to the surface roughness, which could be decreased by $26-74 \%$ in the polishing process; a smooth surface is more resistant to colorant dyeing. Thus, further study should be conducted to ensure that surface roughness and morphology after infiltration treatment are more similar to those of normal enamel.

The results of the present study indicate that for early caries measured using a laser diagnosis pen with readings ranging from 14-30, white spots could be masked to reach a favorable aesthetic effect after treatment with non-invasive infiltration. Furthermore, color stability was maintained under cariogenic conditions.

\section{ACKNOWLEDGMENTS}

Research supported by the Department of Science and Technology of Jiangxi Province (\#2011ZBBG70008) and Technology Bureau of Nanchang City [\#(2012)37 social development support program -1-4].

\section{REFERENCES}

Anderson P and Elliott JC (2000). Rates of mineral loss in human enamel during in vitro demineralization perpendicular and parallel to the natural surface. Caries Res. 34: 33-40.

Belli R, Rahiotis C, Schubert EW, Baratieri LN, et al. (2011). Wear and morphology of infiltrated white spot lesions. $J$. 
Dent. 39: 376-385.

Brodbelt RH, O’Brien WJ, Fan PL, Frazer-Dib JG, et al. (1981). Translucency of human dental enamel. J. Dent. Res. 60: 1749-1753.

Davila JM, Buonocore MG, Greeley CB and Provenza DV (1975). Adhesive penetration in human artificial and natural white spots. J. Dent. Res. 54: 999-1008.

Dietschi D, Campanile G, Holz J and Meyer JM (1994). Comparison of the color stability of ten new-generation composites: an in vitro study. Dent. Mater. 10: 353-362.

Houwink B (1974). The index of refraction of dental enamel apatite. Br. Dent. J. 137: 472-475.

Kim S, Kim EY, Jeong TS and Kim JW (2011). The evaluation of resin infiltration for masking labial enamel white spot lesions. Int. J. Paediatr. Dent. 21: 241-248.

Meyer-Lueckel H and Paris S (2008). Progression of artificial enamel caries lesions after infiltration with experimental light curing resins. Caries Res. 42: 117-124.

Mueller J, Meyer-Lueckel H, Paris S, Hopfenmuller W, et al. (2006). Inhibition of lesion progression by the penetration of resins in vitro: influence of the application procedure. Oper. Dent. 31: 338-345.

Mueller J, Yang F, Neumann K and Kielbassa AM (2011). Surface tridimensional topography analysis of materials and finishing procedures after resinous infiltration of subsurface bovine enamel lesions. Quintessence. Int. 42: 135-147.

Neuhaus KW, Graf M, Lussi A and Katsaros C (2010). Late infiltration of post-orthodontic white spot lesions. J. Orofac. Orthop. 71: 442-447.

Paris S and Meyer-Lueckel H (2010). Infiltrants inhibit progression of natural caries lesions in vitro. J. Dent. Res. 89: 1276-1280

Paris S, Meyer-Lueckel H, Colfen H and Kielbassa AM (2007). Penetration coefficients of commercially available and experimental composites intended to infiltrate enamel carious lesions. Dent. Mater. 23: 742-748.

Paris S, Hopfenmuller W and Meyer-Lueckel H (2010). Resin infiltration of caries lesions: an efficacy randomized trial. J. Dent. Res. 89: 823-826.

Rocha Gomes TC, Borges AB, Torres LM, Gomes IS, et al. (2011). Effect of caries infiltration technique and fluoride therapy on the colour masking of white spot lesions. J. Dent. 39: 202-207.

Theuns HM, Driessens FC, van Dijk JW and Groeneveld A (1986). Experimental evidence for a gradient in the solubility and in the rate of dissolution of human enamel. Caries Res. 20: 24-31.

Wang Y and Tang RY (2005). Current concepts of remineralizing agents. Chin. J. Conservative Dentistry 15: 523-526.

Yamazaki H, Litman A and Margolis HC (2007). Effect of fluoride on artificial caries lesion progression and repair in human enamel: regulation of mineral deposition and dissolution under in vivo-like conditions. Arch. Oral Biol. 52: 110-120. 